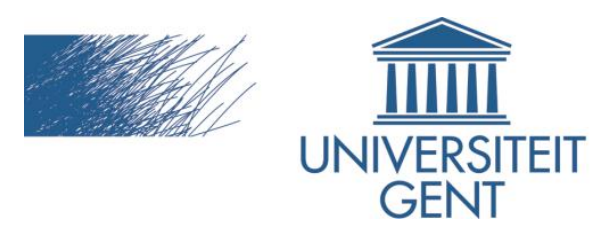

biblio.ugent.be

The UGent Institutional Repository is the electronic archiving and dissemination platform for all UGent research publications. Ghent University has implemented a mandate stipulating that all academic publications of UGent researchers should be deposited and archived in this repository. Except for items where current copyright restrictions apply, these papers are available in Open Access.

This item is the archived author-version of:

Title: The syntax of polarity emphasis

Authors: Anne Breitbarth, Karen De Clercq, Liliane Haegeman

In: Lingua, Special Issue on Polarity Emphasis, 2013.

Optional: link to the article

To refer to or to cite this work, please use the citation to the published version:

Breitbarth, Anne, Karen De Clercq and Liliane Haegeman. 2013. The syntax of polarity emphasis. Lingua. DOI: 10.1016/j.lingua.2013.02.004 


\section{Abstract}

A cross linguistic survey of the expression of polarity emphasis reveals that some such expressions are subject to the distributional constraints typical of main clause phenomena, while others are not. The former have received a fairly homogeneous syntactic analysis, implicating specific left peripheral projections. The non-restricted variety, however, is not analysed uniformly with some phenomena receiving a fully syntactic account and others being accounted for in terms of semantics and pragmatics.

Key words: polarity emphasis, left periphery, focus, Main Clause Phenomena 


\title{
The syntax of polarity emphasis
}

Anne Breitbarth (corresponding author) ${ }^{1}$

\author{
Karen De Clercq $^{2}$
}

Liliane Haegeman ${ }^{3}$

\author{
1 Ghent University \\ Department of Linguistics \\ Muinkkaai 42 \\ 9000 Ghent \\ Belgium \\ anne.breitbarth@ugent.be \\ (+32) 093313274 \\ 2 Ghent University \\ Department of Linguistics \\ Muinkkaai 42 \\ 9000 Ghent \\ Belgium \\ karen.declercq@ugent.be
}




\author{
${ }^{3}$ Ghent University \\ Department of Linguistics \\ Blandijnberg 2 \\ 9000 Ghent \\ Belgium \\ liliane.haegeman@ugent.be \\ (+32) 092643647
}

\title{
1. Introduction
}

While the semantics of polarity emphasis has received considerable attention in the literature (see Repp 2009 for a survey and for references), the syntax of the expression of polarity emphasis has not been the subject of comparable systematic enquiry. A number of recent and independent papers (some of which unpublished work) do address the expression of polarity emphasis in specific languages (Lipták 2003 on Hungarian, Holmberg 2007 on Finnish, Martins 2007 on European Portuguese, Hernanz 2007a, 2007b, 2010 on Spanish, Kandybowicz 2007, 2008 on Nupe, Poletto 2009 on Italian etc.) but by and large, the authors' main concern in these papers was to provide a theoretically-based description of polarity emphasis in the specific language(s) studied, and there is no systematic attempt at cross- 
linguistic comparison and synthesis. However, from these papers it transpires that to some degree the expression of polarity emphasis is rather constant crosslinguistically, a point which so far seems to have escaped notice.

In this paper, we provide an overview on the existing literature on the syntax of polarity emphasis, and we show where analyses converge and where they diverge. The present volume will add to the discussion by bringing together a number of new papers on polarity emphasis: by juxtaposing these papers we hope to bring out the crosslinguistic parallelisms as well as the differences in the expression of polarity emphasis.

\section{Two ways of encoding polarity emphasis: distributional differences}

While each finite clause has a polarity value (with the unmarked value being 'positive'), in certain types of discourse contexts the polarity value of a sentence may be associated with particular emphasis. Typically, polarity emphasis arises when the polarity of the proposition conflicts with that of a background assumption. In English, emphatic do is one way of encoding polarity emphasis, though, as we will see presently, its syntactic properties differ from what seem similar types of expressions of polarity emphasis in other languages. The attested (1) illustrates a typical use of emphatic $d o$ : in this example the proposition 'they stand', with positive polarity, is contrasted with the preceding assertion 'women are not standing', which has negative polarity. In (1) emphatic do focuses on the truth value of the clause, in contrast with the context, and can thus be seen as an expression of Verum Focus (Höhle 1992, Klein 1998, Romero and Han 2004a, 2004b:630, Repp 2009:194 a.o. and see Wilder this volume section 4).

(1) The problem is that women are not standing. When they do stand they have just the same chance of getting the post as a man, but they are not putting themselves forward.

(Observer 22.08.2010, p. 15, col 5)

As discussed in Breitbarth and Haegeman (2009), Danckaert and Haegeman (2012) and Haegeman (2012b), in many languages the syntactic patterns encoding polarity 
emphasis are subject to distributional constraints in that they are restricted to root clauses and to a well defined set of embedded domains. In other words, these expressions of polarity emphasis pattern as root transformations (Emonds 1970, 1976) or main clause phenomena (from now on abbreviated as MCP) (Hooper and Thompson 1973, Heycock 2006, Haegeman 2007, 2012a, 2012b, Aelbrecht et al. 2012). Such patterns have been discussed for Spanish in Hernanz (2007a, 2007b), for the Italian Veneto dialect in Poletto $(2008,2009)$, for European Portuguese in Martins (2007), for Nupe, a Benue-Congo language of central Nigeria, in Kandybowicz (2008) and for Latin in Danckaert (2009). For all these languages, the relevant expressions of polarity are unavailable in central adverbial clauses (Haegeman 2003, 2011, 2012b, Danckaert and Haegeman 2012), restrictive relative clauses, and certain types of complement clauses such as clausal complements of factive verbs. As already illustrated by English emphatic do in (1), other phenomena that also convey polarity emphasis enjoy a much freer distribution as discussed by Danckaert (2009), Danckaert and Haegeman (2012), or Breitbarth and Haegeman (2010, 2011).

The contributions to this volume further investigate the expression of polarity emphasis, broadening the range of empirical data. Specifically, Batllori \& Hernanz, Kandybowicz, Martins, and Poletto and Zanuttini return to the distributionally restricted expressions of polarity emphasis. (2)-(4) illustrate the relevant pattern. This type of polarity emphasis is typically found in reversing reactions to assertions, such as European Portuguese (2), in which polarity emphasis is conveyed by affirmative verb reduplication, Spanish (3), in which it is expressed by sentence initial polarity particles bien and si, and in Nupe (4), in which the sentence final particle ni: conveys polarity emphasis.

(2) a. A: Aquí nunca chove, pois não? B: Chove, chove. here never rains CONFIRM NEG rains rains 'It never rains here, does it? - Yes, it does!'

b. A: Ele não ouve bem. B: ${ }^{*} E u$ sei que ele ouve bem ouve. he neg hears well I know that he hears well hears 'He doesn't hear well._ I know that he does hear well.' 
(Martins, this issue)

(3) a. Bien ha cantado la soprano

indeed has sung the soprano

'The soprano HAS sung'

b. Si(*bien) canta la Caballé, el teatro se llenará

ifindeed sings the Caballé, the theatre SE fill-FU

'If indeed M. Caballé is singing, the theatre will be full.'

(Batllori and Hernanz, this issue)

(4) A: wo labara gànán Musa gí kinkere ni:

3PL hear newscomp Musa eat scorpion NI:

'(I assure you) They DID hear the news that Musa ate the scorpion.'

Not: '(I assure you) They heard the news that Musa DID eat the scorpion.'

(Kandybowicz, this issue)

Other expressions of polarity emphasis however, have a wider distribution. Some examples of these are discussed in Danckaert (2009), Danckaert and Haegeman (2012), and in Breitbarth and Haegeman (2010, 2011). For instance, the Flemish particle en serves to emphasise the negative polarity of the clause. As shown in West Flemish (5), the particle is compatible with conditional clauses, a domain that normally resists MCP (cf. Danckaert and Haegeman 2012). Similarly, as shown by (6), like emphatic do (1), auxiliary focus in English, which also conveys polarity emphasis, is compatible with adverbial clauses. Verb reduplication in Nupe, as discussed in the current volume by Kandybowicz, is also compatible with embedded domains: in (7) it occurs in a complement to $\mathrm{N}$, a domain that is known to resist MCP.

(5) Oa't nie enregent, moe-j deblommen woater geven. if=it NEG EN rain-3SG, must.2SG=you the flowers water give 'If it DOESN'T rain, you must water the flowers.'

(after Haegeman 2007:fn.3)

(6) If he HAS finished the thesis by the end of this year, I'll be surprised.

(Danckaert \& Haegeman 2012:160)

(7) A: wo labara gànán

Musa gí kinkere gí. 
3PL hear newsCOMP Musa eat scorpion eat

'They heard the news that (apparently) Musa DID eat the scorpion.'

(Kandybowicz, this issue)

As shown by Kandybowicz's contribution to this volume, then, it is not the case that languages display either the restricted or the non-restricted variety of polarity emphasis. Nupe is a case in point: it displays both the restricted variety (through the particle ni: ) and the unrestricted variety (through verb reduplication), with subtle differences in interpretation.

Though from (1) and (6) one might conclude that in English the expression of polarity emphasis is unrestricted in distribution, an extension of the data reveals that such a conclusion would be incorrect. Indeed, Wilder (this issue) shows that in English so called emphatic do in fact conveys two distinct types of emphasis: the pattern in (8), which Wilder identifies as the Verum Focus pattern in the sense of Höhle (1992), has an unrestricted distribution and is compatible with domains resisting MCP, but he shows that emphatic do may also convey what he calls a contrastive topic interpretation. In the latter use, emphatic do patterns with MCP and has a restricted distribution (9). We refer to Wilder's paper (esp. section 3.2) for a discussion of the distinct intonation patterns associated with the two types of examples and for full discussion of the two interpretations.

(8) She told me that he didn't treat her politely, so ...

I refused to pay him until he DID treat her politely.

(Wilder, this issue)

(9) a. A: Is he a good doctor? B: Well, he DOES have a lot of PATIENTS.

b. ${ }^{*}$ I wonder if he DOES treat his patients POLITELY.

b'. I DO wonder if he treats his patients POLITELY.

(Wilder, this issue)

Other patterns encoding polarity emphasis in English are also distributionally restricted. For instance, negative preposing, illustrated in (10), which fronts a negative constituent to the left periphery of the clause leading to subject auxiliary inversion (Haegeman 2000a, 2000b, 2012b, Büring 2005) is identified as an 
expression of Verum Focus by Han and Romero (2004: 182). Again, negative preposing is restricted to root and root-like domains (10a), it is incompatible with complement clauses of $N(10 b, c)$, relative clauses (10d), subject clauses (10e) and central adverbial clauses (10f).

(10) a. On no account should you change the analysis to suit the reviewer.

b. $\quad$ *The fact that never has he had to borrow money makes him very proud.

c. *Your notion that never before have the children had so much fun is absurd.

(Hooper and Thompson 1973: 485, their (171))

d. $\quad$ The children that never in their lives had had such fun fell into bed exhausted.

((10d) from Hooper and Thompson 1973: 466, their (4)))

e. $\quad$ *That not once has Mary heard from her children is shocking to Sue.

(Emonds 2004: 77, n. 4)

f. $\quad$ *The deputies could extort with impunity, as long as no less corrupt was the ward boss.

(Emonds 1976: 35)

According to Ward (1988, 1990), VP preposing, as illustrated in the attested (11a), also serves to encode polarity emphasis:

Verb phrase preposing serves two functions in discourse: to affirm a speaker's belief in a salient proposition explicitly evoked in the prior discourse, or to suspend a speaker's belief in such a proposition

(Ward 1990: 742)

(11) a. "But / couldn't rewind time, I just had to get over it." And get over it she did. (Guardian, 6.9.1.,page 15, col 8) 
Once again, English VP preposing is generally considered to be a MCP (Hooper and Thompson 1973, Emonds 1976), witness the fact that it is ungrammatical in embedded domains such as those in (11b-e) (see also Haegeman 2012b: 93-4):

(11) b. *Sally plans for Gary to marry her, and it bothers me that marry her he will.

(Hooper and Thompson 1973: 479, (102))

c. $\quad$ *Sally would like Gary to marry her, but that marry her he will is not true.

d. $\quad$ *Sally plans for Gary to marry her, but the announcement that marry her he will surprised her.

e. $\quad$ *When passed these exams you have, you'll get the degree.

In fact, while the difference in distribution of polarity emphasising expressions observed here has not been the focus of much recent discussion, it had already been noted in the older literature. In a large-scale study of African languages of what they call 'auxiliary focus'- emphatic assertion as expressed through focus on the auxiliary - Hyman and Watters (1984) show that while in many languages, the expression of polarity emphasis is restricted to main clauses, potentially including the types of embedded clause that can be assimilated to them $(1984: 256)^{1}$, in some languages emphatic assertion through auxiliary focus is generally available in all clause types. They propose that in languages in which auxiliary focus is what we call a MCP, "focus marking is grammatically [...] controlled" (1984:256), while in languages in which it is unrestricted, it is "pragmatically controlled". We tentatively take the latter characterisation to imply that the relevant phenomenon is not syntactically encoded, i.e. that the unrestricted variant of the expression of polarity emphasis is not 'syntacticized' (in the sense of Cinque and Rizzi 2010) in those languages.

\section{A syntax for polarity emphasis?}

From the recent discussion of polarity emphasis one is led to the conclusion that expressions of polarity emphasis which are restricted to main clauses seem to be

\footnotetext{
1 Among clause types that resist the focused auxiliary they list relative clauses, temporal clauses, antecedent if-clauses, that is, those types of embedded domains that are typically incompatible with MCP, cf. above.
} 
relatively homogeneous crosslinguistically. Though implementations vary, most syntactic accounts (including Fischer 2000, Fischer and Alexiadou 2001, Holmberg 2007, Hernanz 2007a, 2007b, 2011, Poletto 2008, 2009, Zanuttini 1997, Martins 2006, Kandybowicz 2008) make crucial use of the functional projections of the left periphery. In terms of a split CP along the lines of Rizzi (1997), the derivation of the phenomena in question has been argued to implicate (an operator in) a designated left-peripheral functional projection encoding focus on the polarity of the sentence in these constructions, possibly attracting a lower polarity projection (Laka's 1993, 1994 $\Sigma \mathrm{P}$, for instance). As will become clear in section 3, most contributions to the present volume also adopt this type of analysis, again with varying implementations depending on the authors' theoretical assumptions. We can conclude that previous and current analyses of the distributionally restricted expression of polarity emphasis converge on the view that this expression of polarity emphasis is syntacticized and that it is tied to a specific left peripheral functional domain. The restriction to root clauses and a subset of embedded clauses is accounted for by whatever account is invoked to account for the restricted distribution of other main clause phenomena. We refer to Aelbrecht et al. (2012) for discussion of the various options that have been explored and to Haegeman $(2012 a, b)$ for a syntactic analysis.

On the other hand, on the basis of a cursory survey of some of the relevant data it turns out that those expressions of emphatic polarity that do not display the restricted distribution of MCP do not pattern in a homogeneous way and that they cannot all be subsumed under what Hyman and Watters call 'pragmatically controlled' phenomena that do not receive a syntactic reflex. In particular, both Kandybowicz (this issue) and Batllori and Hernanz (this issue) argue for a syntactic analysis of such expressions of polarity emphasis in Nupe and in Catalan respectively.

Kandybowicz (this issue) proposes that in Nupe, polarity emphasis, as conveyed by verb reduplication, is syntactically encoded even when it is not subject to the distributional restrictions of MCP. Along the lines of, among others, Jayaseelan (1999, 2001, 2008, 2010), Butler (2003) and Belletti (2001, 2004), he assumes that both CP and IP host focal constituents. For Nupe, he argues for the availability of "at least two loci of emphasis": a high left peripheral position and a low TP-internal site. 
An emphatic item in the left peripheral position outscopes polarity operators; the low TP-internal emphatic item is outscoped by polarity operators.

Similarly, Batllori \& Hernanz (this issue, fn. 14) take the syntactic and semantic behaviour of 'low' emphatic polarity particles (EPPA) ben and pas in Catalan (12a) to share properties with what Gallego (2007) calls mild focus which is taken to be merged at the left edge of $\mathrm{LP}$, and Batllori and Hernanz take 'low' EPPA to be located in a functional projection between FinP and VP, above the IP field. 'High' EPPA, such as bé (12b), historically related to ben (< 'well'), cannot occur in this position (12d).
a. La soprano *ben s'ha ben enfadat
the soprano BEN SE=has BEN got-angry
'The soprano has really got angry'
b. Bé ha cantat la soprano indeed has sung the soprano
'The soprano HAS sung'
c. *Béla soprano ha cantat
d. Lasoprano s'ha *bé enfadat

(after Batllori \& Hernanz, this issue)

On the other hand, there are also non-syntactic accounts for the expressions of polarity emphasis that do not seem to be syntactically constrained. Wilder's analysis of emphatic do in English remains closer to Hyman and Watters' pragmatic approach. He distinguishes two interpretations of English emphatic do: (i) Verum Focus, whose distribution is unrestricted, and (ii) a contrastive topic interpretation, which is distributionally restricted. Because both patterns realise affirmative polarity focus, Wilder concludes that the difference in distribution cannot be syntactic in nature. $\mathrm{He}$ therefore proposes a non-syntactic account of this difference. He takes the fall-rise accent $\mathrm{H}^{*} \mathrm{LH} \%$ of the contrastive topic pattern emphatic do to be a grammatical marker with its own meaning: it is related to the implicatures concerning unanswered questions. Wilder proposes to analyse the contrastive topic pattern in terms of Büring's (2003) discourse trees (D-trees), (13). 
is he a good doctor?

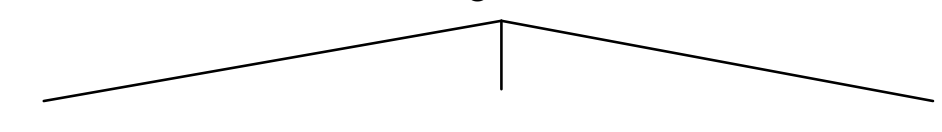

Q2 $\quad$ Q3 $\quad$ Q4

does he have a lot of patients? does he diagnose well? does he treat his patients politely?

A2

he does have a lot of patients

The unrestricted Verum Focus pattern illustrated in (1), on the other hand, is analysed by Wilder as arising because of a focus feature on $\Sigma$, which heads a polarity projection dominating TP (Laka 1993, 1994) (cf. also Martins, this issue). This focus feature is spelled out as a focus accent on the auxiliary. In consequence, the proposition expressed by the do-clause is interpreted as contrasted with its negation.

\section{The present volume}

In this section we present a short overview of the papers in this volume.

Batllori \& Hernanz's contribution provides a detailed taxonomy of emphatic polarity particles (EPPA) in Spanish and in Catalan and develops a syntactic analysis for these. The authors distinguish two types of EPPA, 'high' ones and 'low' ones, where 'high' EPPA are related to the CP layer (in terms of Rizzi 1997) and 'low' EPPA are TP internal. They present evidence for a syntactic analysis under which EPPA are polar elements with an added emphatic value which are merged with PoIP and move to FocusP. It is observed that high EPPA display wh-operator properties. Low EPPA, on the other hand, appear above VP. Batllori \& Hernanz's analysis accounts for the observation that the occurrence of high EPPA, but not that of low EPPA, is constrained to root clauses and to those embedded clauses that have a full-fledged left periphery. 
Kandybowicz's paper investigates the syntax of emphatic assertion in Nupe. Two strategies are available for the expression of polarity emphasis: a clause-final discourse particle ni: or verb doubling, with subtle interpretive differences. The clause-final particle ni: has the restricted distribution of MCP; it encodes a strong veridical interpretation. Verb doubling, on the other hand, is syntactically unrestricted and is interpretively weaker. To capture the distributional and interpretive contrast between the two patterns, Kandybowicz elaborates a fully syntactic account according to which two emphatic domains are projected in the clause: a high left peripheral domain and a low TP internal site. Given that the former does and the latter does not c-command sentential polarity, the scopal effect of the two differs: in the high left periphery the emphatic operator scopes over polarity, in the low IP internal site it is outscoped by polarity. Kandybowicz's proposal is in line with proposals according to which the 'high' left periphery (Rizzi 1997) is replicated at the IP related level (cf. Belletti 2001, 2004, Jayaseelan 1999, 2001, 2008, 2010, Butler 2003)

As was already pointed out, Wilder's contribution contrasts with the two papers discussed above, which fully syntacticize the expression of polarity focus. Wilder shows that there are two uses of emphatic do in English, referred to as Verum Focus and Contrastive Topic, with distinct intonational and semantic-pragmatic properties and with different grammatical distributions. Both instantiations of emphatic do realise affirmative polarity focus. In the Verum Focus (VF) type, do may be the sole focus (They DO work hard), and any additional accent is a focus accent (falling tone); in Contrastive Topic (CT) sentences on the other hand, there is a CT mark - a fall-rise $\left(H^{*} \mathrm{LH} \%\right)$ accent - on a phrase (subject, verb phrase or object) which is expressed by an accent with a final fall-rise tone. Wilder develops a semantic account for these two distinct interpretations of emphatic do in English which also captures the restricted distribution of the CT use.

Wilder argues that CT sentences give rise to special implicatures not associated with VF sentences; and he shows that, unlike the expression of VF and like other instances of contrastive topics in English (cf. Haegeman 2012b for a recent survey), the expression of CT by means of emphatic do is a MCP and hence excluded from (most) embedded environments and questions. Both the specific pragmatic 
properties and the distributional asymmetry of CT patterns with this use of emphatic do are argued to follow in large part from the meaning of the CT marking, which answers one polar question, but implicates a larger discourse-tree with multiple unanswered questions.

Depending on the context in which it occurs, a declarative clause may or may not be associated with an expression of polarity emphasis. On the other hand, polarity emphasis becomes a core part of the interpretation of answers to yes/no question and this is particularly so in answers which reverse the polarity of the question. In such answers the content of the proposition ('IP') is essentially given through the question and the focus of the answer is on the polarity (yes/no). Such answers constitute a core territory for the study of the expression of polarity emphasis. The role of polarity focus in elliptical answers to questions has been discussed in the literature. A number of papers in this volume also focus on the encoding of polarity emphasis in such answers.

Holmberg's contribution focuses on the syntax and interpretation of answers to yes/no questions, i.e. polarity related questions, in English and in Swedish. His paper again endorses the syntactic analysis of polarity emphasis in that he ties such answers directly to the left peripheral Focus projection: a focus particle in the left peripheral Focus is related to the IP-internal polarity variable. Because the content of the IP is given as a result of being part of the yes/no question, it is typically elided. The paper surveys and compares the intricate answering patterns in English and in Swedish, crucially depending on the scope properties of the negation. He distinguishes two fundamental types of answering systems: those that are truthbased (or agreement/disagreement based) and those that are polarity based.

The final three contributions focus on the syntax of correcting or reversing reactions to assertions. All three propose a fully syntacticized analysis, and all three localise the syntactic encoding of emphasis on the polarity in a left-peripheral functional projection. As will become clear from the papers, the syntax of polarity emphasis is closely tied up with that of ellipsis phenomena and with the question of ellipsis licensing (see also Repp 2009 for a recent discussion). 
Lipták analyses the syntactic encoding of conversational moves such as affirmative confirmations and affirmative reversing reactions in relation to default assertions and polar questions in Hungarian. She shows that these conversational moves have a particular syntax, involving a left peripheral projection that hosts a positive polarity specification. She bases this claim on observations concerning two types of ellipsis: the use of igen, a sentence internal affirmative particle which spells out the Polarity head in elliptical clauses where TP is elided, and the use of V-stranding ellipsis in polarity contexts, which is licensed by the Polarity head.

Also Poletto \& Zanuttini's contribution deals with emphatic replies with a polarity particle (si/no) followed by an embedded clause introduced by the declarative complementizer che in Italian ("si che/no che sentences"). They argue that si che/no che sentences are biclausal structures that contain two copies of the triggering utterance: a null copy in a left peripheral hanging topic position located above the polarity particle in the matrix clause and an overt copy contained in the lower checlause. The effect of emphasis is then seen as consequence of this reduplication. This doubling configuration accounts for the fact that these si che/no che sentences (a) are MCP (because they contain a (null) hanging topic) and (b) are restricted regarding their content, which reduplicates that encoded in the left peripheral null copy.

Martins approaches the syntactic expression of emphatic polarity in reversing reactions to assertions in the Romance languages from a comparative perspective. Focussing on European Portuguese, she identifies three syntactic strategies to convey emphatic affirmation: (i) the verb reduplication strategy, (ii) the sentenceinitial si que (AFF that) strategy, also addressed in Poletto \& Zanuttini's contribution in Italian, and (iii) the sentence-final sim/si 'yes' strategy.

Martins argues that the functional categories $\mathrm{C}$ (encoding relative polarity features) and $\Sigma$ (encoding absolute polarity features) are jointly involved in the syntactic expression of emphatic polarity and must be both phonologically realized in the relevant structures. The Romance languages differ with respect to verb movement possibilities in relation to the functional heads $C$ and $\Sigma$ (the topmost head of the IP 
domain) and the specificities of the polarity lexicon. With respect to negative reversals in the context of a previous assertion, Martins identifies two patterns which parallel the sentence-initial si que pattern and the sentence-final sim/si pattern respectively.

\section{Conclusion and outlook}

From the previous literature on expressions of polarity emphasis as well as from the contributions to this volume it emerges that the distributionally restricted expression of polarity emphasis is crosslinguistically relatively stable and can be captured by a syntactic analysis according to which it is encoded in the left peripheral layer, with details of execution dependent on the theoretical framework adopted.

On the other hand, at this stage no such consensus can be formulated with respect to the analysis of the distributionally unrestricted expressions of polarity emphasis and the currently available analyses vary widely: some phenomena are given a semantic /pragmatic account, without any reference to a syntacticization of polarity emphasis, while other phenomena are analysed in terms of a low $\mathrm{VP}$ periphery which mirrors that of the high, clausal, left periphery. These syntactic analyses offer further support for the hypothesis that both $\mathrm{CP}$ and $\mathrm{VP}$ have a discourse related periphery. At this point it is not clear that a homogeneous treatment of all the relevant patterns is desirable or possible and we believe that extending the range of data analysed, including returning in more detail to those data first discussed in Hyman and Watters (1984) will contribute to a better understanding of the phenomenon.

\section{Acknowledgements}

This special issue of Lingua contains a selection of the papers presented at the workshop on Polarity emphasis: distribution and locus of licensing that took place at Ghent University on 29 and 30 September 2011. This event was made possible by funding through Liliane Haegeman's FWO Odysseus grant G091409. We wish to thank all participants for the work and the discussions that have made possible this 
volume, the authors not only for contributing to it, but also, as specialists on polarity emphasis, for acting as 'internal' reviewers on each other's papers, and the anonymous external reviewers selected by Lingua. We would finally like to express our gratitude to the editors of Lingua, Johan Rooryck, Lisa Gordon and in particular Anikó Lipták for their patience and support in the production of this volume.

\section{References}

Aelbrecht, L., Haegeman, L., Nye, R. (Eds.), 2012. Main clause phenomena and the privilege of the root. In: Aelbrecht, L., Haegeman, L. Nye, R. (Eds), Main Clause Phenomena. New Horizons, John Benjamins, Amsterdam, pp. 1-19.

Belletti, A., 2001. Inversion as focalisation. In: Hulk, A., Pollock, J.-Y. (Eds.), Subject Inversion in Romance and the Theory of Universal Grammar, Oxford University Press, Oxford, pp. 60-90.

Belletti, A., 2004. Aspects of the Low IP Area. In: Rizzi, L. (Ed.), The Structure of CP and IP. Oxford University Press, Oxford, pp. 16-51.

Breitbarth, A., Haegman, L., 2010. Continuity is change: The long tail of Jespersen's cycle in Flemish. In: Breitbarth, A. Lucas, C., Watts, S., Willis, D. (Eds.), Continuity and Change in Grammar, John Benjamins, Amsterdam, pp. 61-76.

Breitbarth, A., Haegeman, L., 2011. 'En' en is niet wat we dachten: A Flemish discourse particle. Submitted to the Proceedings of MOSS 2, MITWPL.

Büring, D., 2003. On D-trees, beans, and B-accents. Linguistics and Philosophy 26, 511-545.

Büring, D., 2005. Negative Inversion. In: Bateman, L., Ussery, C. (Eds.), Proceedings of Nels 35. Graduate Linguistic Student Association, South College, University of Massachusetts at Amherst, pp. 1-21

Butler, J., 2003. A minimalist treatment of modality. Lingua 113, 967-996.

Cinque, G., Rizzi, L., 2010. The cartography of syntactic structures. In: Heine, B., Narrog, H. (Eds.), The Oxford handbook of grammatical analysis. Oxford University Press, Oxford, pp. 51-65.

Danckaert, L., 2009. Polarity Focus and the Latin particle quidem in adverbial clauses. Paper presented at the conference on Root Phenomena, Zentrum für Allgemeine Sprachwissenschaft, Berlin, September 2009. 
Danckaert, L., Haegeman, L., 2012. Conditional clauses, Main Clause Phenomena and the syntax of polarity emphasis. In: Ackema, P., Alcorn, R., Heycock, C., Jaspers, D., Van Craenenbroeck, J., Vanden Wyngaerd, G. (Eds.), Comparative Germanic Syntax: The state of the art, John Benjamins, Amsterdam, pp. 133-168.

Emonds, J., 1970. Root and structure-preserving transformations. Ph.D.diss., MIT, Cambridge, MA.

Emonds, J., 1976. A transformational approach to English syntax. Academic Press, New York.

Emonds, J., 2004. Unspecified categories as the key to root constructions. In: Adger, D., De Cat, C., Tsoulas, G. (Eds.), Peripheries: syntactic edges and their effects, Kluwer, Dordrecht, pp. 75-121.

Fischer, S., Alexiadou, A., 2001. On Stylistic Fronting: Scandinavian vs. Romance. Working Papers in Scandinavian Syntax 68. 117-145.

Gallego, Á.J., 2007. Defectivitat morfològica i variació sintàctica. Caplletra 42. 219249.

Haegeman, L., 2000a. Negative preposing, the Neg criterion and the structure of CP. In: Horn, L., Kato, Y. (Eds.), Negation and polarity. Oxford University Press, Oxford, pp. 29-69.

Haegeman, L., 2000b. Inversion, non-adjacent inversion and adjuncts in CP. In: Rowlett, P. (Ed.), Papers from the Salford negation conference, Special Issue of Transactions of the Philological Society 98, pp121-160.

Haegeman, L., 2003. Conditional clauses: external and internal syntax. Mind and Language 18, 317-339.

Haegeman, L., 2007. Operator movement and topicalization in adverbial clauses. Folia Linguistica 41, 279-325.

Haegeman, L., 2009. The movement analysis of temporal adverbial clauses. English Language and Linguistics 13. 385-408.

Haegeman, L., 2010. The internal syntax of adverbial clauses. In: Grohmann, K., Tsimpli, I (Eds.), Exploring the left periphery. Special Issue of Lingua 120. 628648.

Haegeman, L., 2011. The movement derivation of conditional clauses. Linguistic Inquiry 41. 595-621 
Haegeman, L., 2012a. The syntax of MCP: Deriving the truncation account. In: Aelbrecht, L., Haegeman L., Nye, R. (Eds.), Main clause phenomena: New Horizons. John Benjamins (Linguistics Today/ Linguistik Aktuell), Amsterdam, pp. 113-134.

Haegeman, L., 2012b. Adverbial clauses, Main clause phenomena and the composition of the left periphery Oxford University Press, Oxford.

Han, C., Romero, M., 2004. Disjunction, focus and scope. Linguistic Inquiry 35, 197217.

Hernanz, M.L., 2007a. From polarity to modality: some (a)symmetries between bien and sí in Spanish. In: Eguren, L., Fernández Soriano, O. (Eds.), Coreference, modality and focus. John Benjamins, Amsterdam, pp. 133-169.

Hernanz, M.L., 2007b. Emphatic polarity and C in Spanish. In: Brugè, L. (Ed.), Studies in Spanish syntax. Venezia: Libreria Editrice Cafoscarina, pp. 104150.

Hernanz, M.L., 2011. Assertive bien in Spanish and the left periphery. In: Benincà, P., Munaro, N. (Eds.), Mapping the left periphery, Oxford University Press, Oxford, pp. 19-62.

Heycock, C., 2006. Embedded root phenomena. In: Everaert, M., van Riemsdijk, H. (Eds.), The Blackwell companion to syntax. Vol. II, Blackwell, Oxford and Boston, pp. 174-209.

Höhle, T., 1992. Über Verum-Fokus im Deutschen. Linguistische Berichte Sonderheft 4. 112-141.

Holmberg, A., 2007. Null subjects and polarity focus. Studia Linguistica 61/3. 212236.

Hooper, J., Thompson, S., 1973. On the applicability of root transformations. Linguistic Inquiry 4. 465-497.

Hyman, L.M., Watters, J.R., 1984. Auxiliary Focus. Studies in African Linguistics 15/3. 233-273.

Jayaseelan, K., 1999. A Focus Phrase above vP. Proceedings of the Nanzan GLOW, Nanzan University, Nagoya, 195-212.

Jayaseelan, K., 2001. IP-internal Topic and Focus Phrases. Studia Linguistica 55. 39-75. 
Jayaseelan, K., 2008. Topic, focus and adverb positions in clause structure. Nanzan Linguistics 4. 43-68

Jayaseelan, K., 2010. Stacking, stranding, and pied-piping: a proposal about word order. Syntax 13, 298-330.

Kandybowicz, J., 2007. On fusion and multiple copy spell-out: the case of verbal repetition. In: Corver, N., Nunes, J. (Eds.), The copy theory of movement, John Benjamins, Amsterdam, pp. 118-150.

Kandybowicz, J., 2008. The grammar of repetition. John Benjamins, Amsterdam.

Klein, W., 1998. Assertion and Finiteness. In: Dittmar, N., Penner, Z. (Eds.), Issues in the Theory of Language Acquisition: Essays in Honor of Jürgen Weißenborn, Lang, Bern, pp. 225-245.

Laka, I., 1993. Negative fronting in Romance: movement to $\Sigma$.In: Ashby, W.J., Mithun, M. Perissinotto, G. (Eds.), Linguistic perspectives on the Romance Languages (CILT 103), John Benjamins, Amsterdam, pp. 315-333.

Laka, I., 1994. On the Syntax of Negation. Garland, New York, London.

Lipták, A., 2003. The expression of sentential emphasis in Hungarian. Ms. University of Leiden.

Martins, A.M., 2007. Double realization of verbal copies in European Portuguese emphatic affirmation. In:Corver, N., Nunes, J. (Eds.), The Copy Theory of Movement, John John Benjamins, Amsterdam, pp. 77-118.

http://www.clul.ul.pt/equipa/amartins/Martins_2007_1_artigo.pdf

Poletto, C., 2009. The syntax of focus negation. Ms. University of Venice.

http://hdl.handle.net/10278/989

Repp, S., 2009. Negation in Gapping. Oxford University Press. Oxford.

Rizzi, L., 1997. The Fine Structure of the Left Peripery. In: Haegeman, L. (Ed.), Elements of Grammar: Handbook in Generative Syntax, Kluwer, Dordrecht, pp. 281-337.

Romero, M., Han, C., 2004. Verum focus in negative yes/no questions and Ladd's $\mathrm{p} / \neg \mathrm{p}$ ambiguity. Linguistics and Philosophy 27, 609-658.

Romero, M.,Han, C., 2004b. On Negative Yes/No Questions, Linguistics and Philosophy 27. 609-58.

Ward, G.L., 1988. The Semantics and Pragmatics of Preposing. Garland Publishing, New York. 
Ward, G.L., 1990. The discourse functions of VP preposing. Language 66, 742-763.

Zanuttini, R., 1997. Negation and Clausal Structure: A Comparative Study of Romance Languages. Oxford University Press, Oxford. 